\title{
The Droopy Breast and Treatment Modalities
}

\section{Petrus V van Deventer* \\ Department of Plastic and Reconstructive Surgery, Faculty of Health Sciences, University of Stellenbosch, Republic of South Africa}

*Corresponding author: Petrus V van Deventer, M.B.Ch.B., M.Med.Sc., M.Med.(Plast. \& Rekons. Chir.), Department of Plastic and Reconstructive Surgery, Faculty of Health Sciences, University of Stellenbosch, Republic of South Africa, E-mail: pvvandeventer@gmail.com

\section{Introduction}

Breasts play an important physical and psychosexual role in the lives of women and should, therefore, be in perfect condition.

Drooping of the breast can be corrected with a variety of surgical techniques.

If the breasts are small and the droopiness is not too severe, a breast augmentation can be performed with the introduction of silicone prostheses. This might automatically lift the breast without any other surgical adjustment.

The main disadvantage of using a silicone prosthesis would be the foreign body reaction, causing encapsulation of the prosthesis with connective tissue, which, in some instances can cause hardening and/or deformation of breast shape. Regardless of the type of prosthesis used, be it gel filled, saline filled, smooth or textured surface, capsular contraction can still occur. Four different grades can occur ranging from grade 1 (almost natural to touch) to grade 4 (a deformed, hard and painful breast).

The mass of a normal breast is approximately 300 $\mathrm{g}$, which can enlarge to about $500 \mathrm{~g}$ during lactation. It is therefore unwise to introduce prostheses larger than $300 \mathrm{~g}$ in the breast, which can increase the risk of potential complications. For instance loss of nipple sensation, rippling, extrusion and stretch marks.

Breasts can also be enlarged via fat grafting, which has shown excellent results with few complications. However, at this stage, it is not frequently performed by plastic surgeons because of the long operation time and multiple sessions required for a satisfactory result.

In patients with severe drooping of the breasts and adequate breast tissue, another technique is used by combining a breast lift and breast tissue excision as well as the introduction of silicone prostheses. This technique combines the potential risks of 2 procedures which is unnecessary and irrational. If there is adequate breast tissue in the droopy breast, why not rearrange the existing tissue so that if forms a normal looking breast and utilize a technique to maintain its shape? This can be done without silicone augmentation. However, it is generally agreed upon by world renowned plastic surgeons that these procedures only have a temporary result in most instances. The reason for this is that the very same tissues that stretched previously are utilized in the surgical technique and may stretch again over time.

To overcome this problem of recurrent drooping of breasts after the surgery, Goes [1,2], has used a mesh for internal breast support since 1990. At that stage it was then generally believed that breast shape was maintained by the ligaments described by Cooper [3]. These ligaments connect the glandular component of the breast to the skin. It is difficult to believe though, that these ligaments can prevent displacement of the breast relative to the chest wall that occur with the droopy breast.

At the end of the previous century, supportive structures in the breast were described by Würinger $[4,5]$ in 1997 i.e. a ligamentous suspension of the breast and



INTERNATIONAL LIBRARY

Citation: van Deventer PV (2018) The Droopy Breast and Treatment Modalities. Int J Womens Health Wellness 4:071. doi.org/10.23937/2474-1353/1510071

Received: May 16, 2016: Accepted: May 22, 2018: Published: May 24, 2018

Copyright: (C) 2018 van Deventer PV. This is an open-access article distributed under the terms of the Creative Commons Attribution License, which permits unrestricted use, distribution, and reproduction in any medium, provided the original author and source are credited. 
in 2013 by Matousek, et al. [6], a fascial supporting network. This new knowledge opened the door to the development of an alternative technique to prevent post-operative recurrent drooping of the breasts.

A South African plastic surgeon, Peet van Deventer [7], with the aid of the Breform company developed a technique in that regard.

The function of the failed supportive structures of the breast were successfully replaced with a biocompatible non-absorbable mesh. Research was done under the supervision of the ethics committee at the University Stellenbosch, Western Cape, South Africa. Initially, an anatomical study was performed to design a technique whereby mesh could be inserted into the breast, beneath the skin, and attached to the chest wall with the least damage to the blood vessels and nerves. The aim was also to evoke minimal scarring. Female cadavers were used for this purpose. Once satisfied that the procedure would be safe, 15 voluntary trial patients had surgery to determine which kind of breasts would benefit most from the procedure. The first operation was done in 2004 and the following conclusions were drawn from the trial:

1. The best results were obtained with patients that had normal sized breasts.

2. Excellent results could be obtained even in patients with severe droopiness. The degree of droopiness did not affect the end result at all.

3. The best results were obtained with patients that had a normal body mass index of between 20 and 25 .

4. Enlarged breasts must be reduced to obtain satisfactory results. There is a limit to the amount of breast tissue that can be supported effectively with the mesh. Less satisfactory results were obtained if more than $500 \mathrm{~g}$ of breast tissue must be supported.

5. On the other hand, there should be enough breast tissue to lift, because the technique does not enlarge the breast but gives the illusion of a larger breast.

6. Complications encountered by the patients compared well to those experienced with conventional breast lift and reduction procedures. These include loss of nipple sensation $3.6 \%$, infection $0.9 \%$, fat necrosis $1.3 \%$, blistering of the nipple $0.4 \%$, post-operative bleeding $0.4 \%$ and scarring $0.9 \%$.

There are potential risks involved with the procedure and patients should be carefully selected. The most important aspect is the effect on the blood supply to the nipple and all previous breast surgeries must be taken into account. This technique of internal breast support with mesh relies on certain blood vessels that supply the nipple and they can be jeopardised by previous surgery, for example a breast augmentation. The procedure may then be too risky to perform. Patients that smoke are also excluded.
Excellent and long term results can be obtained with the longest follow up to date of 12 years. The procedure is ideally suited for the post-child-bearing patient with droopy breasts and an adequate amount of breast tissue.

The technique can also be applied in patients with loss of upper breast fullness after inferior pedicle reductions to improve the cosmetic appearance.

It can also be used in patients with droopy breasts due to weight loss after gastric bypass surgery.

In post-mastectomy breast reconstruction procedures, it can be used in the contralateral breast to match the shape of the reconstructed breast.

Radiographic breast examination is still possible post mesh implantation with adequate visualization of the breast tissue.

The technique does not enlarge the breast but supports the breast tissue in its normal anatomical position, giving the illusion of a more youthful larger breast with upper breast fullness. Careful preoperative evaluation of the patient in this regard is very important.

A prerequisite for the technique, therefore, entails an adequate amount of breast tissue to elevate and support with the mesh. Inadequate breast volume will lead to unsatisfactory patients and suboptimal results. It is not advisable to perform silicone augmentation procedures afterwards as the surgical creation of a pocket will disrupt the attachments of the mesh, jeopardising the blood supply to the NAC. A better option for those patients would be fat grafting with the benefit of placing the fat in the areas needed.

The technique is based on sound anatomical principles and excellent and long term results can be obtained regarding breast shape, nipple stand and short inconspicuous scars.

Further information regarding this technique and results can be viewed on the internet [8] or on the website www.breastsurgery.co.za.

\section{References}

1. Goes JC (1996) Periareolar mammaplasty: Double skin technique with application of polyglactin or mixed mesh. Plast Recons Surg 97: 959-968.

2. Goes CJS (2002) Periareolar mammaplasty: Double-skin technique with application of mesh support. Clin Plastic Surg 29: 349-364.

3. Cooper AP (1840) On the anatomy of the breast. Pascal Brooke Bland: Longman, Orme, Green, Brown \& Longmans: London, Harrison \& Co printers, 48-52.

4. Würinger E, Mader N, Posch E, Holle J (1998) Nerve and vessel supplying ligamentous suspension of the mammary gland. Plast Reconstr Surg 101: 1486-1493.

5. Würinger E, Tschabitscher M (2002) New aspects of the topographical anatomy of the mammary gland regarding its neurovascular supply along a regular ligamentous suspension. Eur J Morphol 40: 181-189. 
6. Matousek SA, Corlett RJ, Ashton MW (2014) Understanding the fascial supporting network of the breast: Key ligamentous structures in breast augmentation and proposed system of nomenclature. Plast Reconstr Surg 133: 273281.

7. Van Deventer PV, Graewe FR, Würinger E (2012) Improv- ing the longevity and results of mastopexy and breast reduction procedures: Reconstructing an internal breast support system with biocompatible mesh to replace the supporting function of the ligamentous suspension. Aesthetic Plast Surg 36: 578-589.

8. https://link.springer.com/article/10.1007\%2Fs00266-011-9845-2 